\title{
Three-dimensional laparoscopy: is it as good as it looks? -a review of the literature
}

\author{
Carmen Yim ${ }^{1 *}$, Chun Hin Lo ${ }^{1 *}$, Ming Him Lau ${ }^{1}$, Rachel Fan ${ }^{1}$, Hei Ming Lai ${ }^{2}$, Dominic Chi Chung Foo ${ }^{3}$ \\ ${ }^{1}$ Li Ka Shing Faculty of Medicine, The University of Hong Kong, Hong Kong, China; ${ }^{2}$ School of Biomedical Science, Li Ka Shing Faculty of \\ Medicine, The University of Hong Kong, Hong Kong, China; ${ }^{3}$ Department of Surgery, The University of Hong Kong, Hong Kong, China \\ Contributions: (I) Conception and design: DC Foo; (II) Administrative support: DC Foo; (III) Provision of study materials or patients: C Yim, CH Lo, \\ MH Lau, R Fan, HM Lai; (IV) Collection and assembly of data: C Yim, CH Lo, MH Lau, R Fan, HM Lai; (V) Data analysis and interpretation: C \\ Yim, CH Lo, MH Lau, R Fan, HM Lai; (VI) Manuscript writing: All authors; (VII) Final approval of manuscript: All authors. \\ *These authors contributed equally to this work. \\ Correspondence to: Dominic Chi Chung Foo, MBBS. Department of Surgery, The University of Hong Kong, Hong Kong, China. Email: ccfoo@hku.hk.
}

\begin{abstract}
Technological advancement has benefited minimal invasive surgery substantially. In terms of enhanced operative vision, three-dimensional (3D) laparoscopy provides binocular depth perception, which was absent in the past with the conventional two-dimensional (2D) laparoscopy. There have been a number of studies comparing the use of 2D and 3D laparoscopy over the years and they were reviewed in this article. Essentially, 3D laparoscopy resulted in better performance time and lower error rates with specific tasks in experimental settings, and this was seen in surgeons across different levels of experience. The advantage in terms of operative and clinical outcome was equivocal, with some studies demonstrated faster operating time and less blood loss while others showing similar results. Long-term results in this aspect are scarce. Despite these, surgeons appeared to prefer 3D laparoscopy to the conventional 2D imaging system. Nevertheless, there are still questions to be answered and the role of 3D laparoscopy can be better defined with evidence from future studies.
\end{abstract}

Keywords: Three-dimensional (3D) laparoscopy

Received: 30 June 2017; Accepted: 01 August 2017; Published: 22 August 2017.

doi: 10.21037/ales.2017.08.01

View this article at: http://dx.doi.org/10.21037/ales.2017.08.01

\section{Introduction}

Laparoscopy enabled the advent of minimally invasive surgery, encompassing many advantages such as smaller surgical wounds, less postoperative pain and shorter hospital stays $(1,2)$. However, it also has its unique limitations (3); one of them being loss of depth perception and surgeons need to acquire the psychomotor skills to work with two-dimensional (2D) images. Three-dimensional (3D) laparoscopy has been introduced to address this issue.

3D imaging techniques were available for many years, but initial data had yet to demonstrate any advantages of the $3 \mathrm{D}$ technology over the $2 \mathrm{D}$ version. This might be attributed to the suboptimal image quality, poor illumination and high equipment cost with earlier prototypes (4). Recent technological breakthrough in

(c) Annals of Laparoscopic and Endoscopic Surgery. All rights reserved. stereoscopy has greatly enhanced the image quality. With high-definition resolution being the new standard, results from earlier trials are now obsolete. Yet, the benefits of 3D laparoscopy remained controversial. To better define the role of 3D laparoscopy, we reviewed the evidence behind the application of 3D laparoscopy, as well as discussing the limitations of the current technology. The following review included experimental and clinical trials comparing $3 \mathrm{D}$ and 2D laparoscopy in abdominal, pelvic and gynaecological surgery over the past 10 years.

\section{Principles of 3D laparoscopy}

Depth perception is the ability to estimate and interpret the relative distances of different objects by our eyes. The 
Table 1 Summary of experimental studies comparing task performance of 2D and 3D laparoscopy within the last 5 years

\begin{tabular}{|c|c|c|c|c|c|}
\hline Study & Year & 3D equipment & Cohort size & Tasks & Results \\
\hline $\begin{array}{l}\text { Honeck } \\
\text { et al. (9) }\end{array}$ & 2012 & $\begin{array}{l}\text { Einstein, Scholly 3D } \\
\text { imaging system }\end{array}$ & $\begin{array}{l}\text { 20: } 10 \text { novices, } 10 \\
\text { experienced }\end{array}$ & $\begin{array}{l}5 \text { tasks: ring placement, ring } \\
\text { transfer, needle passage, suture } \\
\text { cutting, knot tying }\end{array}$ & $\begin{array}{l}\text { 3D showed: no difference } \\
\text { on performance time; errors } \\
\text { in some tasks }\end{array}$ \\
\hline $\begin{array}{l}\text { Smith } \\
\text { et al. (8) }\end{array}$ & 2012 & Not specified & 20 novices & $\begin{array}{l}4 \text { tasks: rope pass, paper cut, } \\
\text { needle capping, knot tying }\end{array}$ & $\begin{array}{l}\text { 3D showed: performance } \\
\text { time; errors, especially } \\
\text { more complex tasks }\end{array}$ \\
\hline $\begin{array}{l}\text { Tanagho } \\
\text { et al. (13) }\end{array}$ & 2013 & Viking 3DHD & $\begin{array}{l}\text { 33: } 25 \text { novices, } 8 \\
\text { intermediate/experts }\end{array}$ & $\begin{array}{l}3 \text { FLS tasks: peg transfer, pattern } \\
\text { cutting, suturing/knot tying }\end{array}$ & $\begin{array}{l}\text { 3D showed: performance } \\
\text { time; errors }\end{array}$ \\
\hline $\begin{array}{l}\text { Usta } \\
\text { et al. (14) }\end{array}$ & 2015 & Viking 3DHD & $\begin{array}{l}\text { 24: } 8 \text { novices, } 8 \text { minimally } \\
\text { experienced, } 8 \text { experienced }\end{array}$ & $\begin{array}{l}6 \text { reported tasks: needle transfer, } \\
\text { needle pass, bead transfer, left/ } \\
\text { right hand suture, bead transfer } \\
\text { and drop }\end{array}$ & $\begin{array}{l}\text { 3D showed: performance } \\
\text { time in some tasks; errors } \\
\text { in some tasks }\end{array}$ \\
\hline
\end{tabular}

2D, two-dimensional; 3D, three-dimensional; FLS, fundamentals of laparoscopic skills.

human brain estimates the depth of the object based on five major principles: stereopsis, parallax, depth of field, environmental context, and tactile feedback. Parallax is the difference in relative positions of objects as the observer move and views the objects from different point of views, in which monocular vision is sufficient. On the other hand, stereopsis relies on the identification of disparities between two eyes in binocular vision to allow the brain to compute the relative depth of an object (4). When viewing a motion picture on a monitor, as in the case of a laparoscopic procedure with the conventional 2D laparoscopy, stereopsis is lost and relative distance is perceived by analyzing visual clues. 3D laparoscopy uses two cameras instead of one to recapitulate the effect of human binocular vision: producing two different views of the same object, which are then codisplayed on the screen with oppositely polarized lights. Eyeglasses containing oppositely arranged polarizing filters on each side allow each eye to view differently in accordance with the two cameras' arrangement, permitting depth perception by stereopsis. It is worthy of note that not everyone possess the ability to perceive depth by stereopsis, and $3 \mathrm{D}$ laparoscopy would not have any additional effects in these individuals.

\section{Experimental trials on task performance}

Studies evaluating the performance of various laparoscopic tasks were predominantly based on experimental trials. Currently, there is no consensus on the choice of tasks for comparison. The majority of tasks in these studies were from validated curriculum of basic laparoscopy training, such as fundamentals of laparoscopic skills (FLS) and basic laparoscopic urologic surgery (BLUS) (5-7). Examples included peg transfer, rope pass, paper cut, needle capping and knot tying. For outcome measurement, parameters used for comparisons included average performance time and error rate of individual tasks as well as the whole set of exercise.

The results from these experimental trials were consistent in demonstrating variable degrees of benefit in shortening 
performance time and reducing error rates in $3 \mathrm{D}$ laparoscopy over 2D laparoscopy. Smith et al. compared the performance time of four laparoscopic tasks by 20 novices, showing a significant improvement with 3D laparoscopy $(\mathrm{P}<0.001)$, with an average of $35.8 \%$ difference (8). Honeck et al. concluded operators benefited from 3D laparoscopy regardless of experience level, with $89.6 \%$ error reduction (1.34 vs. $0.14, \mathrm{P}<0.0001)$ in the expert group and $71.6 \%$ error reduction $(2.57$ vs. $0.73, \mathrm{P}<0.0001)$ in the novice group (9). While some of these benefits may potentially be translated into better task performance in in vivo setting (see below), others have shown equivocal results $(9,10)$. Limitations of these studies included small sample size, discrepancy in the classification of experience levels of the subjects, heterogeneity in tasks used for comparison and difference in test equipment (Table 1) (8-14).

\section{Clinical trials on operative outcomes}

In addition to the experimental trials, there were trials comparing the clinical use of 3D and 2D laparoscopy. In a single-surgeon cohort study by Bove et al., the operative data of 3D and 2D laparoscopic radical prostatectomy in 86 patients with prostate cancer was compared (15). The study showed that $3 \mathrm{D}$ laparoscopy significantly reduced the mean total operating time (241 vs. 162 minutes, $\mathrm{P}=0.010$ ), the mean anastomosis time ( 32 vs. 24 minutes, $\mathrm{P}=0.030$ ) and the mean number of anastomosis stitches used (6.45 vs. 5.65, $\mathrm{P}=0.018)$. Currò et al. conducted a randomized controlled trial on laparoscopic cholecystectomy, involving both experienced and novice surgeons, and yielded mixed results (16). A significantly shorter operating time was observed in novice surgeons (60 vs. 48 minutes, $\mathrm{P}=0.02$ ), but not in experienced surgeons (40 vs. 38 minutes, $\mathrm{P}=0.10)$. Table 2 summarized published clinical trials on 3D laparoscopy $(15,16,19,20,22)$. Given the heterogeneity of the study design and their mixed results, it is hard to conclude that $3 \mathrm{D}$ laparoscopy is superior to $2 \mathrm{D}$ laparoscopy in clinical use. More data are required to demonstrate if $3 \mathrm{D}$ imaging system results in shorter operating time, and whether such advantage is consistent across different types of surgical procedures and with surgeons of different experience levels.

In terms of intraoperative blood loss, two studies found statistically significant differences between 2D and 3D laparoscopies $(18,21)$. Lu et al. demonstrated in a randomized controlled trial that $3 \mathrm{D}$ laparoscopic gastrectomy resulted in reduced blood loss compared to $2 \mathrm{D}$ laparoscopic gastrectomy (78 vs. $58 \mathrm{~mL}, \mathrm{P}=0.047)$ (21). This was echoed by another retrospective study by Aykan et al. which demonstrated less blood loss in 3D laparoscopic radical prostatectomy (138 vs. $102 \mathrm{~mL}, \mathrm{P}<0.001)(18)$. However, similar finding was not seen in studies involving other surgical procedures $(17,23,24)$.

With regard to postoperative complication, hospital stay and operative mortality, the current literature did not show any difference between 2D and 3D laparoscopic procedures $(17,21,23)$. For example, Velayutham et al. compared 3D and 2D laparoscopic hepatectomy and demonstrated similar complication rates: bile leak $(\mathrm{P}>0.999)$, postoperative ascites $(\mathrm{P}>0.999)$ and respiratory complications $(\mathrm{P}=0.544)(24)$. The two groups were also comparable in terms of the severity grading of complications, i.e., minor complications (Clavien I to II complications) and major complication rates (Clavien III to IV complications). There was no postoperative mortality observed in both groups.

Regarding long-term outcomes, Aykan et al. showed a higher 3 months post-radical prostatectomy continence rate in the 3D laparoscopy group (50\% vs. $25 \%, \mathrm{P}=0.020)(18)$. However, long-term results were generally limited and remained a subject of future research.

\section{Surgeons perspective}

Several surveys suggested that surgeons subjectively preferred 3D laparoscopy over 2D laparoscopy (13,25-28). Tanagho et al. studied 33 subjects performing four standardized laparoscopic tasks from the FLS skill set (13). $81.8 \%$ of the subjects found 3D laparoscopy improved their performance, and $87.9 \%$ indicated that they preferred $3 \mathrm{D}$ to $2 \mathrm{D}$ laparoscopy. Spille et al. further evaluated preference among different levels of experience (27). A total of 277 subjects from three subgroups (students, residents and specialists) were required to perform four laparoscopic tasks with both $3 \mathrm{D}$ and 2D laparoscopies and they were asked to fill in a questionnaire afterwards. Overall, $68.8 \%$ of the participants preferred 3D to 2D laparoscopy and this was consistent within all three subgroups.

Kinoshita et al. compared surgeon's self-rated satisfaction score and their choice of imaging system with certain tasks in laparoscopic radical prostatectomy (19). The satisfaction score was significantly higher in 3D laparoscopy (4.2 vs. 3.1, 
Table 2 Summary of clinical trials comparing task performance of 2D and 3D laparoscopy

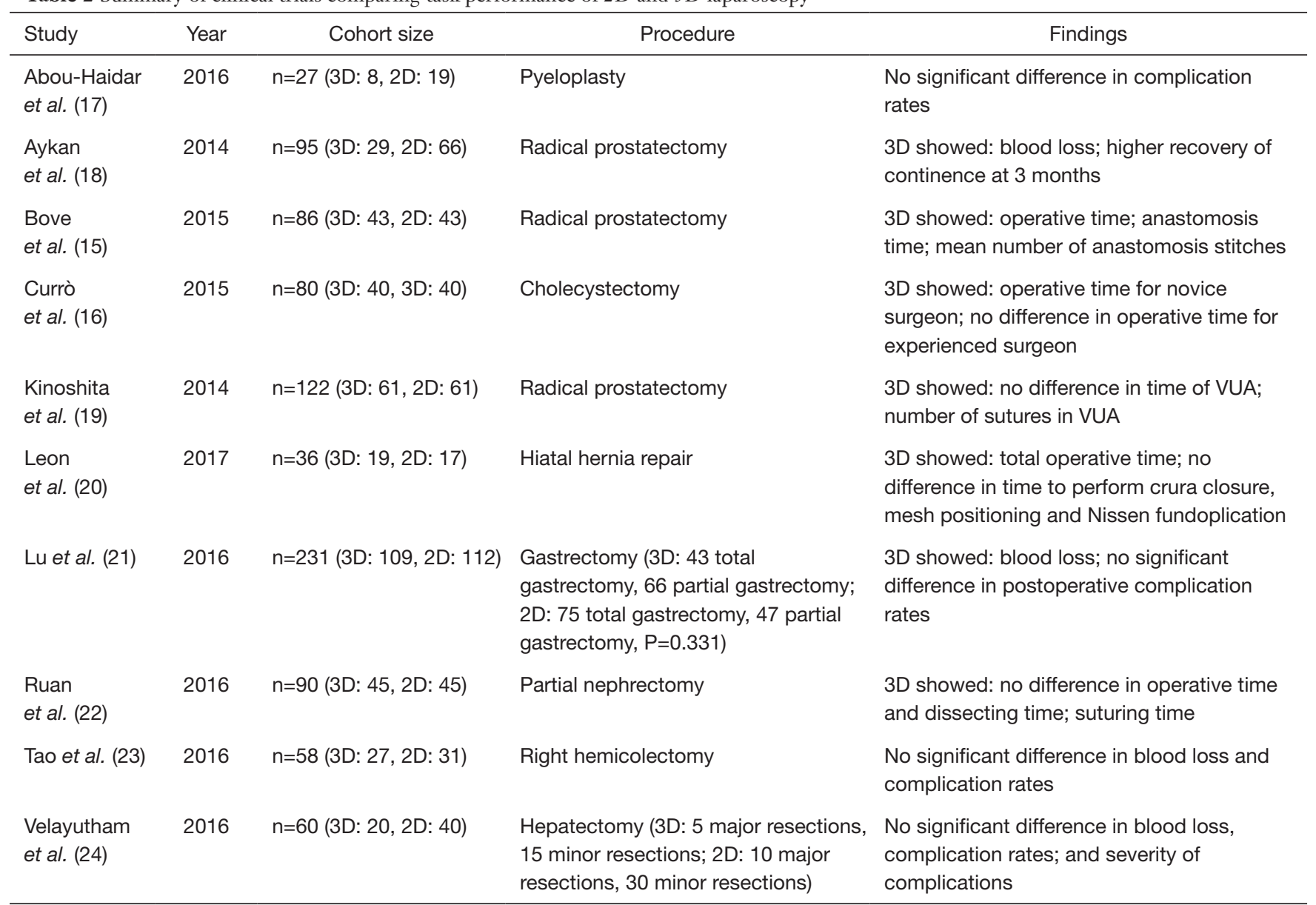

2D, two-dimensional; 3D, three-dimensional; VUA, vesicourethral anastomosis.

0 being lowest, 6 being highest, $\mathrm{P}<0.001)$. Surgeons also preferred 3D laparoscopy with certain tasks like moving instruments to an intended position $(4.4$ vs. $3.1, \mathrm{P}<0.001)$ and adjusting the needle direction ( 4.5 vs. 2.7, $\mathrm{P}<0.001)$.

Headache, nausea and eye strain from 3D laparoscopy have been reported (29-32), although these were not consistently demonstrated across different studies and subjects $(13,14)$. Three studies reported increased adverse reactions with $3 \mathrm{D}$ laparoscopy $(25,30,33)$. In a randomized prospective study by Usta $e t$ al., 24 participants were required to perform 10 standardized tasks and asked to report any adverse reactions experienced when using $3 \mathrm{D}$ or $2 \mathrm{D}$ laparoscopy. There was no difference in visual strain $(\mathrm{P}=0.087)$, headache $(\mathrm{P}=0.134)$ or facial discomfort $(\mathrm{P}=0.090)$ (14). Gómez-Gómez et al. measured the mental workload using the NASA Task Load Index with five standardized tasks. Although 3D laparoscopy produced a smaller mental workload, more adverse reactions such as dizziness and headache were reported (33).

\section{Limitations of 3D laparoscopy}

As mentioned previously, 3D laparoscopy has the advantage of allowing depth perception. However, a normal stereopsis is a prerequisite for individuals to experience this effect. In a study by Bloch et al., stereopsis-normal and stereopsisabsent subjects were recruited to perform simulated fine motor surgical tasks under 2D and 3D systems respectively. Results showed that the two groups demonstrated comparable performance with 2D laparoscopy, while the stereopsis-absent group had poorer performance compared to the stereopsis-normal group using 3D laparoscopy (34). 
An evaluation regarding stereopsis in surgeons by Biddle et al. revealed that $74-83 \%$ of surgeons possessed highgrade stereopsis while $2-14 \%$ had reduced stereopsis (35). Another study by Fergo et al. found that $10 \%$ of the evaluated surgeons did not have measurable stereopsis (36). The implication of these two studies was that approximately $10 \%$ of surgeons would not be able to appreciate depth perception despite 3D laparoscopy.

\section{Limitations of the current literature}

Experimental trials on simple task performance, albeit their superior results with $3 \mathrm{D}$ laparoscopy, may not necessarily reflect the complexity of real-life surgeries. Some randomized control trials had limited sample sizes with possible biases and type II errors, and this might partly explain the mixed results aforementioned in this review. It remained a possibility that $3 \mathrm{D}$ laparoscopy might benefit certain types of surgical procedures but not others. Even so, the main effect would be in terms of facilitating certain tasks and reducing operating time. Operative outcome, and ultimately patient care, however, is affected by a multitude of factors, and the effect of a mere enhanced vision is expected to be small. Studies have to possess a formidably large sample in order to detect such effect. Even if such advantage existed, cost-effectiveness is another issue, which was hardly addressed. Nevertheless, the 'upgrading' of minimally invasive surgery theatres with $3 \mathrm{D}$ laparoscopies is expected to press on, in the hope that surgeons would benefit from advancing technologies, despite limitations with the current evidences.

\section{Conclusions}

The current technology of 3D laparoscopic imaging system provided depth perception and spatial orientation, which was absent in conventional 2D system. This revolutionized laparoscopic surgery with enhanced operative vision and studies have demonstrated enhanced results in experimental settings with faster performance time and lower error rates. However, evidence was still inconclusive on whether this translates into better operative outcomes. Future randomized control clinical trials on a larger scale with more patient-related long-term outcomes will be of benefit. But perhaps it is ultimately up to the decision of individual surgeons and institutions whether binocular vision would help with their work in a way that additional cost is justified.

\section{Acknowledgements}

None.

\section{Footnote}

Conflicts of Interest: The authors have no conflicts of interest to declare.

\section{References}

1. Tjandra JJ, Chan MK. Systematic review on the shortterm outcome of laparoscopic resection for colon and rectosigmoid cancer. Colorectal Dis 2006;8:375-88.

2. Leung KL, Kwok SP, Lam SC, et al. Laparoscopic resection of rectosigmoid carcinoma: prospective randomised trial. Lancet 2004;363:1187-92.

3. Gallagher AG, O'Sullivan GC. Fundamentals of Surgical Simulation. 1 ed. London: Springer-Verlag London, 2012.

4. McDougall EM, Soble JJ, Wolf JS Jr, et al. Comparison of three-dimensional and two-dimensional laparoscopic video systems. J Endourol 1996;10:371-4.

5. Kowalewski TM, Sweet R, Lendvay TS, et al. Validation of the AUA BLUS Tasks. J Urol 2016;195:998-1005.

6. Sweet RM, Beach R, Sainfort F, et al. Introduction and validation of the American Urological Association Basic Laparoscopic Urologic Surgery skills curriculum. J Endourol 2012;26:190-6.

7. Hur HC, Arden D, Dodge LE, et al. Fundamentals of laparoscopic surgery: a surgical skills assessment tool in gynecology. JSLS 2011;15:21-6.

8. Smith R, Day A, Rockall T, et al. Advanced stereoscopic projection technology significantly improves novice performance of minimally invasive surgical skills. Surg Endosc 2012;26:1522-7.

9. Honeck P, Wendt-Nordahl G, Rassweiler J, et al. Threedimensional laparoscopic imaging improves surgical performance on standardized ex-vivo laparoscopic tasks. J Endourol 2012;26:1085-8.

10. Alaraimi B, El Bakbak W, Sarker S, et al. A randomized prospective study comparing acquisition of laparoscopic skills in three-dimensional (3D) vs. two-dimensional (2D) laparoscopy. World J Surg 2014;38:2746-52.

11. Lusch A, Bucur PL, Menhadji AD, et al. Evaluation of the impact of three-dimensional vision on laparoscopic performance. J Endourol 2014;28:261-6.

12. Storz P, Buess GF, Kunert W, et al. 3D HD versus 2D 
HD: surgical task efficiency in standardised phantom tasks. Surg Endosc 2012;26:1454-60.

13. Tanagho YS, Andriole GL, Paradis AG, et al. 2D versus $3 \mathrm{D}$ visualization: impact on laparoscopic proficiency using the fundamentals of laparoscopic surgery skill set. J Laparoendosc Adv Surg Tech A 2012;22:865-70.

14. Usta TA, Ozkaynak A, Kovalak E, et al. An assessment of the new generation three-dimensional high definition laparoscopic vision system on surgical skills: a randomized prospective study. Surg Endosc 2015;29:2305-13.

15. Bove $P$, Iacovelli $V$, Celestino $F$, et al. $3 \mathrm{D}$ vs $2 \mathrm{D}$ laparoscopic radical prostatectomy in organ-confined prostate cancer: comparison of operative data and pentafecta rates: a single cohort study. BMC Urol 2015;15:12.

16. Currò G, La Malfa G, Lazzara S, et al. Three-Dimensional Versus Two-Dimensional Laparoscopic Cholecystectomy: Is Surgeon Experience Relevant? J Laparoendosc Adv Surg Tech A 2015;25:566-70.

17. Abou-Haidar H, Al-Qaoud T, Jednak R, et al. Laparoscopic pyeloplasty: Initial experience with 3D vision laparoscopy and articulating shears. J Pediatr Urol 2016;12:426.e1-426.e5.

18. Aykan S, Singhal P, Nguyen DP, et al. Perioperative, pathologic, and early continence outcomes comparing three-dimensional and two-dimensional display systems for laparoscopic radical prostatectomy--a retrospective, single-surgeon study. J Endourol 2014;28:539-43.

19. Kinoshita H, Nakagawa K, Usui Y, et al. Highdefinition resolution three-dimensional imaging systems in laparoscopic radical prostatectomy: randomized comparative study with high-definition resolution twodimensional systems. Surg Endosc 2015;29:2203-9.

20. Leon P, Rivellini R, Giudici F, et al. 3D Vision Provides Shorter Operative Time and More Accurate Intraoperative Surgical Performance in Laparoscopic Hiatal Hernia Repair Compared With 2D Vision. Surg Innov 2017;24:155-61.

21. Lu J, Zheng CH, Zheng HL, et al. Randomized, controlled trial comparing clinical outcomes of $3 \mathrm{D}$ and $2 \mathrm{D}$ laparoscopic surgery for gastric cancer: an interim report. Surg Endosc 2017;31:2939-2945.

22. Ruan Y, Wang XH, Wang K, et al. Clinical evaluation and technical features of three-dimensional laparoscopic partial nephrectomy with selective segmental artery clamping. World J Urol 2016;34:679-85.
23. Tao K, Liu X, Deng M, et al. Three-Dimensional Against 2-Dimensional Laparoscopic Colectomy for Right-sided Colon Cancer. Surg Laparosc Endosc Percutan Tech 2016;26:324-7.

24. Velayutham V, Fuks D, Nomi T, et al. 3D visualization reduces operating time when compared to high-definition 2D in laparoscopic liver resection: a case-matched study. Surg Endosc 2016;30:147-53.

25. Ko JK, Li RH, Cheung VY. Two-dimensional versus three-dimensional laparoscopy: evaluation of physicians' performance and preference using a pelvic trainer. J Minim Invasive Gynecol 2015;22:421-7.

26. Romero-Loera S, Cárdenas-Lailson LE, de la ConchaBermejillo F, et al. Skills comparison using a 2D vs. 3D laparoscopic simulator. Cir Cir 2016;84:37-44.

27. Spille J, Wenners A, von Hehn U, et al. 2D Versus 3D in Laparoscopic Surgery by Beginners and Experts: A Randomized Controlled Trial on a Pelvitrainer in Objectively Graded Surgical Steps. J Surg Educ 2017. [Epub ahead of print].

28. Kong SH, Oh BM, Yoon H, et al. Comparison of twoand three-dimensional camera systems in laparoscopic performance: a novel 3D system with one camera. Surg Endosc 2010;24:1132-43.

29. Cicione A, Autorino R, Laguna MP, et al. Threedimensional Technology Facilitates Surgical Performance of Novice Laparoscopy Surgeons: A Quantitative Assessment on a Porcine Kidney Model. Urology 2015;85:1252-6.

30. Zhou J, Xu HJ, Liang CZ, et al. A Comparative Study of Distinct Ocular Symptoms After Performing Laparoscopic Surgical Tasks Using a Three-Dimensional Surgical Imaging System and a Conventional Two-Dimensional Surgical Imaging System. J Endourol 2015;29:816-20.

31. Guanà R, Ferrero L, Garofalo $S$, et al. Skills Comparison in Pediatric Residents Using a 2-Dimensional versus a 3-Dimensional High-Definition Camera in a Pediatric Laparoscopic Simulator. J Surg Educ 2017;74:644-649.

32. Chan AC, Chung SC, Yim AP, et al. Comparison of twodimensional vs three-dimensional camera systems in laparoscopic surgery. Surg Endosc 1997;11:438-40.

33. Gómez-Gómez E, Carrasco-Valiente J, Valero-Rosa $\mathrm{J}$, et al. Impact of 3D vision on mental workload and laparoscopic performance in inexperienced subjects. Actas Urol Esp 2015;39:229-35.

34. Bloch E, Uddin N, Gannon L, et al. The effects of absence 
of stereopsis on performance of a simulated surgical task in two-dimensional and three-dimensional viewing conditions. Br J Ophthalmol 2015;99:240-5.

35. Biddle M, Hamid S, Ali N. An evaluation of stereoacuity (3D vision) in practising surgeons across a range of surgical

doi: 10.21037/ales.2017.08.01

Cite this article as: Yim C, Lo CH, Lau MH, Fan R, Lai HM, Foo DC. Three-dimensional laparoscopy: is it as good as it looks? - a review of the literature. Ann Laparosc Endosc Surg 2017;2:131. specialities. Surgeon 2014;12:7-10.

36. Fergo C, Burcharth J, Pommergaard HC, et al. Age is highly associated with stereo blindness among surgeons: a cross-sectional study. Surg Endosc 2016;30:4889-4894. 